\title{
Age wins as Tokyo revamps retirement rules
}

David Cyranoski, Tokyo

The University of Tokyo is to extend the mandatory age of retirement from 60 to 65 , despite criticism from some of its former professors. The increase will be phased in between 2001 and 2013, adding one year to the retirement age every three years.

The proposal has been hotly contested since it was put forward last December. Critics argue that it will enhance the power of established professors and block already congested career paths for young researchers. But the university president, Shigehiko Hasumi, says that the extension will help to move the university towards a "global standard" based on "diversity of nationality, sex and age".

Ken'ichi Arai, director of the university's Institute of Medical Science and a member of its senate, agrees. He says that flatly refusing to let those over 60 continue their work is age discrimination and a barrier to producing a university system "based purely on achievement".

Detractors allege, however, that the initiative is motivated not by lofty principles of equal opportunity, but by a desire to protect would-be retirees from declining post- retirement employment prospects and changes in Japan's pension system.

In Japan, the pensionable age for public employees, including university professors, is also being raised from 60 to 65 - on the same 13-year schedule as at the university. In addition, the once-abundant opportunities for retired professors to augment a scanty pension with positions in private universities have been drying up.

Takashi Masuda, who retired from the university's faculty of sciences this March, believes that eliminating the need for retirees to seek employment elsewhere will make professors complacent. He has set up a webpage to air the opinions of faculty opposed to the change.

Extending the retirement age will make it more difficult for young researchers to get positions, Masuda says. This will be especially harmful in the sciences, he adds, where the most productive work is often done by scholars in their $30 \mathrm{~s}$ or 40 s.

Supporters and critics of the age change agree that its effectiveness will rest on new evaluation systems and other relevant policies that university departments must imple-

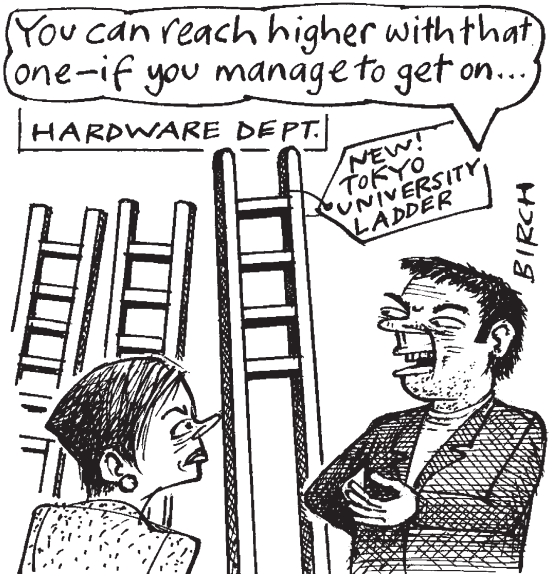

ment as it comes into force.

Although optimists see the initiative as part of a larger move towards an achievement-orientated university system, others are less sanguine. According to Masuda, the change was passed by the university senate with no real debate, and little serious consideration will be given to improving the evaluation system, either. "The department heads won't want to make any hard decisions that they don't have to," he says.

http://www-masuda.cs.uec.ac.jp/ masuda/

\section{Frozen body offers chance to travel back in time}

\section{Quirin Schiermeier and Katrin Stehle}

Six European research groups are eagerly awaiting new samples from the bones, teeth and intestine of Ötzi, the Stone Age man whose body was defrosted last week.

Ötzi's frozen body, over 5,000 years old, was found in 1991 in the Italian Alps close to the Austrian border. It was examined by local researchers for several years before being moved to a specially built museum of archaeology in Bolzano in Italy - under armed guard in case of attacks by Austrian nationalists (see Nature 391, 318; 1998).

Since then, tempers have cooled and a more coordinated approach has been established. A scientific committee set up in 1998 comprises researchers from Austria, Switzerland and Italy, and is chaired by Horst Seidler, co-director of the Institute of Anthropology at the University of Vienna.

Six projects have been selected for study. Scientists are particularly interested in analysing Ötzi's genetic make-up, if this proves technically possible. They hope to address medical, pathological and anthropological questions by examining bacterial DNA in his gut flora, to study genetic similarities with modern Europeans, and to learn about migration patterns and diseases in the late Neolithic period.
Previous examinations included isolation and analysis of mitochondrial DNA from tissue samples. But as only the surface of Ötzi's body was warmed up, data from many

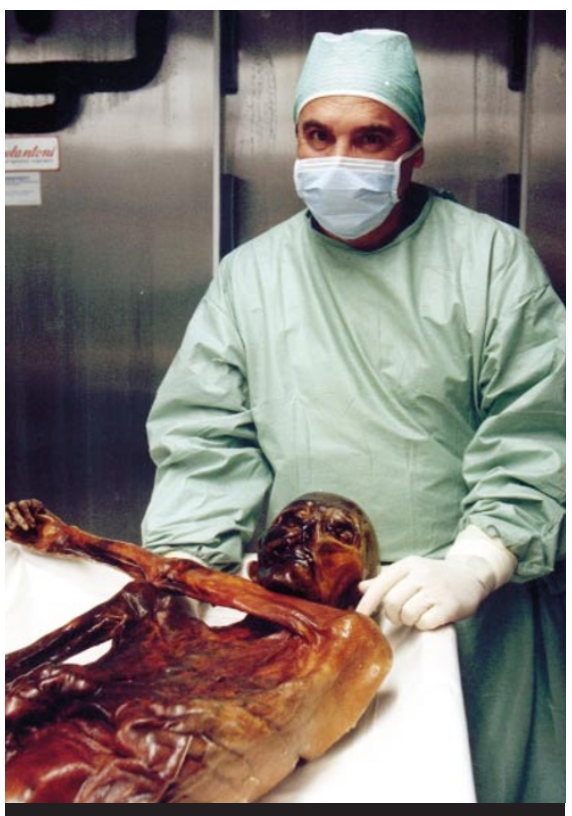

The iceman cometh: Ötzi's fully defrosted body should yield high-quality samples for analysis. samples were of low quality. Samples from the completely defrosted body should be more reliable and more readily comparable with other preserved human bodies.

In one of the projects, Franco Rollo, a professor of anthropology at the University of Camerino in Italy, plans to obtain bacterial genetic sequences from the iceman's intestine. Rollo hopes to determine Ötzi's eating habits and the distribution of pathogenic bacteria at the time he was alive.

Another research group, headed by Mark Thomas of the Centre for Genetic Anthropology at University College London, plans to investigate European migration patterns by comparing the iceman's Y-chromosome with genetic dispositions found among contemporary populations.

Another question concerns Ötzi's geographical origins. Wolfgang Müller, a researcher at the Institute for Isotope Geology at the Technical University of Switzerland in Zürich, hopes that the proportion of strontium and lead isotopes in Ötzi's tooth enamel will help provide the answer. If the quality of the enamel samples is high enough, Müller also wants to look into the oxygen isotopes they contain. This could help to determine the temperature conditions during Ötzi's early youth, he says. 